\title{
Jahresbericht 2015
}

Die Hilfskasse für Schweizer Aerzte unterstützte während des vergangenen Jahres 15 (2014: 11) ohne eigene Schuld in materielle Not geratene Ärztinnen und Ärzte sowie Angehörige und Nachkommen von verstorbenen Kolleginnen und Kollegen.

Neu hinzu kamen im Jahr 2015 drei fortlaufende Unterstützungen und ein einmaliger Unterstützungsbeitrag.

Auf der Ertragsseite stehen Einnahmen aus Spenden von 114405.90 CHF (2014: 108006) sowie Zinsen und Dividenden des Stiftungskapitals von $86633.30 \mathrm{CHF}$ (2014: 69407).

Beim Aufwand haben wir Ausgaben für Unterstützungen von 132000 CHF (2014: 95000). Die Ausgaben für Geschäftsführung und Vermögensverwaltung beliefen sich auf 68800 CHF.

Die Differenz zwischen Einnahmen aus Spenden sowie Zins- und Dividendenertrag aus Kapital und den Aufwendungen für Unterstützungen und Verwaltung führte zu Mehreinnahmen zugunsten des Stiftungsvermögens von 308.65 CHF.

Die sehr hoch erscheinenden Ausgaben für Geschäftsführung und Vermögensverwaltung mögen hier vielleicht auffallen, für eine stabile und den Vorschriften entsprechende Stiftung müssen diese aber aufgebracht werden, denn nur so genügen wir den von Amtes wegen nötigen Überprüfungen einer Stiftung mit uneingeschränkter Steuerbefreiung. Diese wiederum erlaubt uns, auch einmal einen grösseren Spendenbetrag entgegennehmen zu können.

Spendenbeträge unter 500 CHF, die wir zur Minimierung unserer Verwaltungskosten nicht einzeln verdanken können, bilden den traditionellen Grundstock unserer Stiftung; diese seien deshalb an dieser Stelle ganz herzlich verdankt.
Die Jahresrechnung der Hilfskasse wurde von der Firma Marin Treuhand AG revidiert und für in Ordnung befunden. Für ihre Arbeit sei herzlich gedankt. Einzelheiten zur Jahresrechnung können der nachfolgenden Bilanz und Erfolgsrechnung entnommen werden.

Das Stiftungsvermögen ist in einem Mix aus Obligationen und Aktien, der den Vorschriften für die berufliche Vorsorge BVG entspricht, angelegt.

Erfolgsrechnung und Bilanz sowie Verwaltung des Stiftungsvermögens werden jährlich durch die BVGund Stiftungsaufsicht beider Basel überprüft.

Die Tätigkeit des Stiftungsrates erfolgt ehrenamtlich.

Ich danke allen Kommissionsmitgliedern für ihre Arbeit, die sie im vergangenen Jahr geleistet haben. Mein Dank geht auch an die Herren J. Kobler und A. Billich von der Notenstein La Roche Privatbank AG für die Buchhaltung und Vermögensverwaltung.

Die Stiftungskommission der Hilfskasse für Schweizer Aerzte

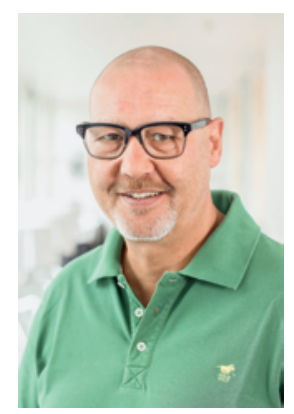

Dr. U. Lüscher, Präsident (Foto)

Frau Dr. S. Stöhr

Dr. U. Leibundgut, Kassier

PC-Konto der Hilfskasse für Schweizer Aerzte: 40-644-3 Basel 


\section{Jahresrechnung 2015}

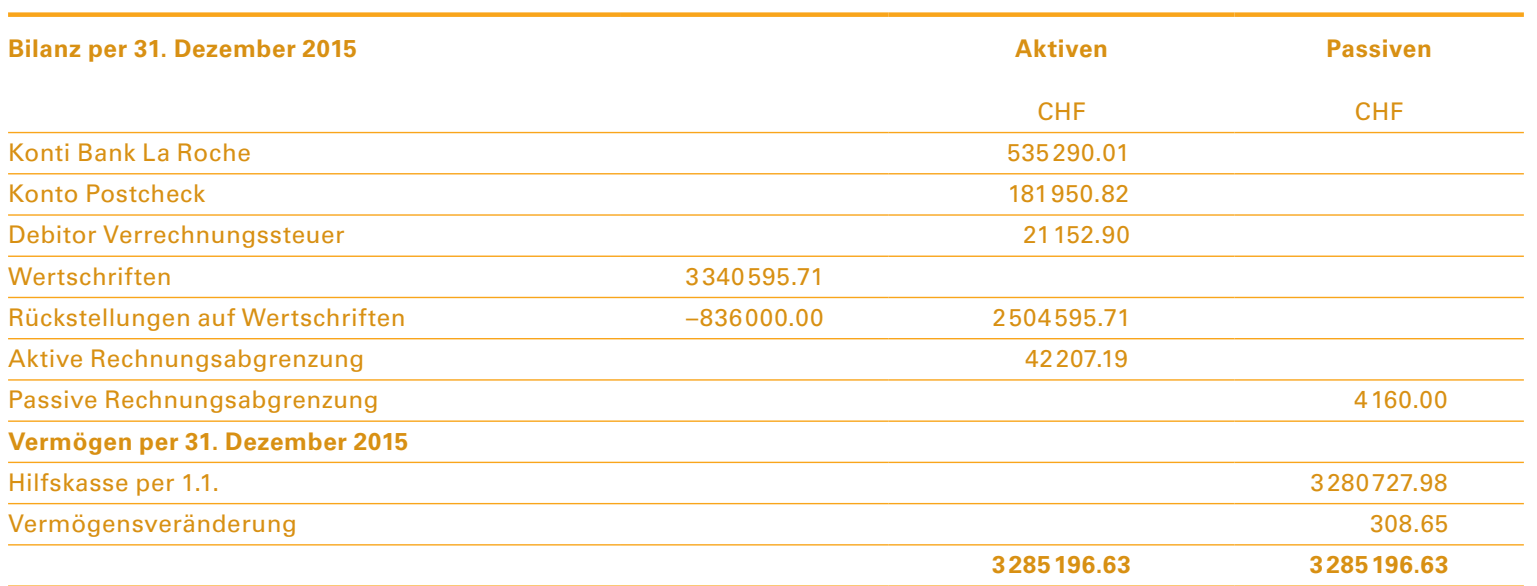

\begin{tabular}{lrr}
\hline Erfolgsrechnung $\mathbf{2 0 1 5}$ & Aufwand & Ertrag \\
& CHF & 114405.90 \\
\hline Spenden, Zeugnisgelder & 86633.30 \\
\hline Kapitalertrag & 15000.00 \\
\hline Auf. Rückstellung Kursdifferenzen & 15258.93 \\
\hline Kursgewinne FW-Konti & 132000.00 \\
\hline Real. Kursverluste auf Wertschriften & 28825.32 & 328.42 \\
\hline Unterstützungen & 39974.72 \\
\hline Bankspesen & 308.65 \\
\hline Verwaltungsspesen & $\mathbf{2 1 6 3 6 7 . 6 2}$
\end{tabular}

